\title{
A INCLUSÃO ESCOLAR NO CONTEXTO DO ENSINO MÉDIO: ANÁLISE DAS PRODUÇÕES EM PERIÓDICO CIENTÍFICO
}

\author{
LA INCLUSIÓN ESCOLAR EN EL CONTEXTO DE LA ENSENÃNZA \\ SECUNDÁRIA: ANÁLISIS DE LAS PRODUCIONES EN PERIÓDICO \\ CIENTÍFICO
}

\author{
INCLUSION IN HIGH SCHOOL CONTEXT: ANALYSIS OF PRODUCTIONS IN \\ A SCIENTIFIC JOURNAL
}

\author{
Natália Costa de FELICIO ${ }^{1}$ \\ Juliane Ap. de Paula PEREZ CAMPOS ${ }^{2}$
}

RESUMO: Considerando a inclusão escolar dos alunos público-alvo da Educação Especial no Ensino Médio, o presente estudo caracterizou-se como pesquisa de revisão sistemática, o qual analisou os trabalhos publicados na Revista Ibero-Americana de Estudos em Educação, entre os anos de 2006 a 2015. Os descritores utilizados para a busca foram: Ensino Médio, Educação Especial, Inclusão Escolar, Pessoa com deficiência. Os resultados mostraram que dos 400 trabalhos publicados em todas as edições pesquisadas, apenas dois contemplaram o tema em questão: um deles tratou sobre a inclusão de alunos com síndrome de Down no Ensino Fundamental e Médio; e o outro discutiu sobre o ensino de física para alunos surdos. Portanto, é importante que as produções científicas voltem sua atenção para a modalidade do Ensino Médio, afinal, os alunos público-alvo da Educação Especial estão conseguindo adentrar e ter acesso às classes regulares; é preciso analisar como está ocorrendo tal processo e como o ensino tem sido organizado para contemplar tais alunos.

PALAVRAS-CHAVE: Educação especial. Ensino médio. Inclusão escolar. Alunos público-alvo da educação especial.

RESUMEN: Considerando la inclusión escolar de los alumnos de la Educación Especial en la Enseñanza Secundaria, el presente estudio se caracterizó por ser una revisión sistemática que analiza los trabajos publicados en la Revista Iberoamericana de Estudios en Educación, entre los años 2006 a 2015. Los descriptores utilizados para la búsqueda fueron: Enseñanza Secundaria, Educación Especial, Inclusión Escolar, Persona con discapacidad. Los resultados mostraron que de los 400 trabajos publicados en todas las ediciones, apenas dos trabajos contemplaron el tema en cuestión: el primero de ellos trató la inclusión de alumnos con síndrome de Down en la

1 Universidade Federal de São Carlos (UFSCar), SP - Brasil. Mestre em Educação Especial pelo Programa de Pós-Graduação em Educação Especial. Integrante do Grupo de Estudos e Pesquisas sobre a Escolarização da Pessoa com Deficiência (GEPEPD). Email: natifelicio@msn.com

${ }^{2}$ Universidade Federal de São Carlos (UFSCar), SP - Brasil. Professora adjunta do Departamento de Psicologia. Doutora em Educação Especial e - Licenciatura em Educação Especial da Universidade Federal de São Carlos (UFSCar). Docente responsável pelo Grupo de Estudos e Pesquisas sobre a Escolarização da Pessoa com Deficiência (GEPEPD). Email: jappcampos@gmail.com 
Enseñanza Fundamental y Secondaria, mientras que el otro, versó sobre la enseñanza de física para alumnos sordos. Por lo tanto, es importante que las producciones científicas vuelvan a prestar una cierta atención a la modalidad de la Enseñanza Secundaria, una vez que, los alumnos de la Educación Especial están consiguiendo adentrarse y tener acceso a las clases regulares. En consecuencia, es necesario analizar cómo está ocurriendo ese proceso y cómo la enseñanza está organizada para contemplar estos alumnos.

PALAVRAS CLAVE: Educación especial. Enseñanza secondária. Inclusión escolar. Alumnos de la educación especial.

ABSTRACT: Considering the inclusion of Special Education students in High School, this study was characterized as a systematic review, which analyzed the studies published in the Ibero-American Journal of Studies in Education, between the years 2006 to 2015. The descriptors used for the search were: High School, Special Education, Inclusion, and Person with disabilities. The results showed that among the 400 papers published in all editions; only two works included the subject in question. One of them approached the inclusion of students with Down syndrome in primary and secondary education; the other discussed the teaching of Physics for deaf students. Therefore, it is necessary that scientific productions turn their attention to the modality of High School, since the Special Education students are managing to enter and have access to regular education, being necessary to analyze how is happening this process and how the school has been organized to contemplate them.

KEYWORDS: Special education. High school. Inclusion. Special education students.

\section{Introdução}

O cenário da educação brasileira vem se modificando nas últimas décadas devido aos movimentos e lutas pela democratização do acesso à escolarização básica e inclusão escolar, para aqueles indivíduos que historicamente foram excluídos do ensino regular (MENDES, 2006).

Em relação ao direito à educação, o Decreto no 6949, de 25 de agosto de 2009, que promulga a Convenção Internacional sobre os Direitos das Pessoas com Deficiência, estabelece que seja assegurado um sistema educacional inclusivo em todos os níveis, bem como o aprendizado ao longo de toda a vida do sujeito. Além disso, ficou decretado que

a) As pessoas com deficiência não sejam excluídas do sistema educacional geral sob alegação de deficiência e que as crianças com deficiência não sejam excluídas do ensino primário gratuito e compulsório ou do ensino secundário, sob alegação de deficiência;

b) As pessoas com deficiência possam ter acesso ao ensino primário inclusivo, de qualidade e gratuito, e ao ensino secundário, em 
igualdade de condições com as demais pessoas na comunidade em que vivem. (BRASIL, 2009, p.12)

A fim de regulamentar e complementar tal normativa, o Decreto $\mathrm{n}^{\circ} 7611$, de 17 de novembro de 2011, o qual dispõe sobre a educação especial, o atendimento educacional especializado e dá outras providências, passa a considerar público-alvo da Educação Especial (PAEE) as pessoas com deficiência, com transtornos globais do desenvolvimento e com altas habilidades ou superdotação; sendo dever do Estado garantir um sistema educacional inclusivo em todos os níveis, sem discriminação e com base na igualdade de oportunidades (BRASIL, 2011).

De acordo com o Censo Escolar da Educação Básica (2013) realizado pelo Instituto Nacional de Estudos e Pesquisas Educacionais Anísio Teixeira (INEP), ao se verificar o número de matrículas dos alunos PAEE em âmbito nacional, comparando todos os níveis de ensino, pode-se notar que o acesso à escolarização em classes comuns vem sendo ampliado; porém, há uma evasão muito grande ao se observar os dados da transição do Ensino Fundamental para o Ensino Médio, conforme demonstrado na Tabela 1 a seguir.

Tabela 1: Número de Matrículas na Educação Especial por etapa de ensino - Brasil $(2007-2013)$

\begin{tabular}{c|c|c|c|c|c}
\hline \multicolumn{7}{|c}{ Alunos incluídos nas Classes Comuns } \\
\hline Ano & Total & Ed. Infantil & Fundamental & Médio & EJA \\
\hline 2007 & 306.136 & 24.634 & 239.506 & $\mathbf{1 3 . 3 0 6}$ & 28.295 \\
\hline 2008 & 375.775 & 27.603 & 297.986 & $\mathbf{1 7 . 3 4 4}$ & 32.296 \\
\hline 2009 & 387.031 & 27.031 & 303.383 & $\mathbf{2 1 . 4 6 5}$ & 34.434 \\
\hline 2010 & 484.332 & 34.044 & 380.112 & $\mathbf{2 7 . 6 9 5}$ & 41.385 \\
\hline 2011 & 558.423 & 39.367 & 437.132 & $\mathbf{3 3 . 1 3 8}$ & 47.425 \\
\hline 2012 & 620.777 & 40.456 & 485.965 & $\mathbf{4 2 . 4 9 9}$ & 50.198 \\
\hline 2013 & 648.921 & 42.982 & 505.505 & $\mathbf{4 7 . 3 5 6}$ & 51.074 \\
\hline
\end{tabular}

Fonte: Dados organizados pela autora com base no Censo Escolar de 2013 (BRASIL, 2014a).

Ao analisar os dados da Tabela 1, nota-se que as matrículas dos alunos PAEE estão concentradas no Ensino Fundamental. Isso mostra que estes alunos não estão avançando na mesma proporção para os níveis subsequentes de ensino, conforme foi destacado anteriormente.

Em contrapartida, os dados sugerem que os alunos PAEE estão conseguindo adentrar nas classes comuns, pois, antes, eram segregados, ou então tinham classes especiais destinadas à sua escolarização. De certa forma, há um avanço em relação ao acesso destes alunos no cenário do ensino regular. Todavia, o processo de inclusão 
escolar também precisa garantir permanência e uma educação de qualidade; para tal, a escola ainda precisa percorrer um longo caminho para que seja de fato considerada inclusiva, já que é necessário que se reorganize para conseguir atender adequadamente tais alunos.

Especificamente em relação ao Ensino Médio, os dados do Censo Escolar mostram que em 2007 existiam 13.306 alunos PAEE matriculados nesse nível de ensino. Esse número cresceu para 47.356 em 2013 (BRASIL, 2014a). Desse modo, fazse necessário discutir tal questão, uma vez que os alunos PAEE estão tendo acesso ao Ensino Médio, porém pouco se estuda de como tem sido o processo de escolarização destes alunos, quais as dificuldades que veem enfrentando, assim como suas demandas, para lhes garantir uma educação de qualidade.

Segundo a Resolução n ${ }^{\circ}$ 2, de 30 de janeiro de 2012, a qual define as Diretrizes Curriculares Nacionais para o Ensino Médio, fica estabelecido que este segmento educacional é um direito social de cada pessoa, e dever do Estado na sua oferta pública e gratuita a todos (BRASIL, 2012).

Ademais, o atual Plano Nacional de Educação (2014-2024), dentre as 20 metas a serem alcançadas pelo país, afirma que se pretende:

Meta 3: universalizar, até 2016, o atendimento escolar para toda a população de 15 (quinze) a 17 (dezessete) anos e elevar, até o final do período vigência deste PNE, a taxa líquida de matrículas no ensino médio para $85 \%$ (oitenta e cinto por cento).

Meta 4: universalizar, para a população de 4 (quatro) a 17 (dezessete) anos com deficiência, transtornos globais de desenvolvimento e altas habilidades e superdotação, o acesso à educação básica e ao atendimento educacional especializado, preferencialmente na rede regular de ensino, com a garantia de sistema educacional inclusivo, de salas de recursos multifuncionais, classes, escolas ou serviços especializados, públicos ou conveniados. (BRASIL 2014b, p. 10 - 11)

Cabe às instituições de ensino garantir a articulação das ações dos serviços da Educação Especial no Ensino Médio, como também eliminar as barreiras físicas, de comunicação e de informação que possam restringir a participação e a aprendizagem dos alunos PAEE. Sendo assim, as escolas devem definir formas inclusivas para atender estes alunos, seja implementando salas de recursos multifuncionais; apoiando a formação continuada dos professores para o atendimento educacional especializado; adequando arquitetonicamente os prédios; instaurando núcleos de acessibilidade, dentre outras ações (BRASIL, 2013). 
Vale ressaltar que o Ensino Médio se configura como a última etapa da Educação Básica (BRASIL, 1996), e é dever do Estado garantir o acesso a todos os cidadãos que procuram cursar qualquer modalidade de ensino, como também é direito do cidadão ter uma educação de qualidade (BRASIL, 1988); ao se considerar todos, também estamos nos referindo aos alunos PAEE.

Com base no que foi exposto, o objetivo deste estudo foi analisar as produções científicas que abordam temas acerca da inclusão de alunos público-alvo da Educação Especial no Ensino Médio, visto que tal assunto é pouco explorado e merece destaque dentro da área da educação em geral, e, mais especificamente, da Educação Especial.

\section{Método}

O presente estudo caracterizou-se como pesquisa de revisão sistemática, o qual buscou “[...] encontrar o maior número possível de resultados de uma maneira organizada" (KOLLER; COUTO; HOHENDORFF, 2014, p. 56), analisando de forma crítica e reflexiva os materiais que já foram publicados sobre a questão a ser investigada.

\section{Procedimento de coleta de dados}

A fonte de dados utilizada foi a Revista Ibero-Americana de Estudos em Educação (RIAEE), uma publicação que abre espaço para trabalhos vinculados à área da Educação e seus diversos temas, tais como: Educação Especial; Formação do Educador; Trabalho Docente e Práticas Pedagógicas, entre outros. A criação da revista se deu a partir de parceria entre a Universidad de Alcalá de Henares (Espanha), e a Faculdade de Ciências e Letras da UNESP (Campus de Araraquara). Seu primeiro exemplar é do ano de 2006.

A coleta de dados dos trabalhos ocorreu desde o primeiro exemplar, 2006, até a última edição da revista posta no ar até data de confecção da pesquisa, 2015 - Edição Especial sobre Políticas de Inclusão e Formação na Educação Superior, contemplando todos os volumes. Desse modo, foram analisados os trabalhos publicados na revista neste período de dez anos, a incluir artigos nacionais e internacionais. 
O foco do estudo foi selecionar os trabalhos que tratassem de temáticas referentes ao Ensino Médio, Educação Especial, Inclusão Escolar, Pessoa com Deficiência. Sendo assim, dos 400 artigos publicados neste espaço de dez anos, foram selecionados 76 que atendiam ao critério da pesquisa.

A seguir, será apresentada a Tabela 2, com maiores informações sobre o ano de publicação e quantos trabalhos foram encontrados em cada volume/número das revistas.

Tabela 2: Total de Artigos Publicados na Revista Ibero-Americana (2006-2015)

\begin{tabular}{|c|c|}
\hline $\begin{array}{c}\text { 2006 } \\
\text { Volume 1; Número } 1=12 \text { trabalhos } \\
\text { Volume 1; Número } 2=12 \text { trabalhos } \\
\text { Total: } \mathbf{2 4}\end{array}$ & $\begin{array}{c}\text { 2007 } \\
\text { Volume 2; Número } 1=12 \text { trabalhos } \\
\text { Volume 2; Número } 2=11 \text { trabalhos } \\
\text { Total: } \mathbf{2 3}\end{array}$ \\
\hline $\begin{array}{c}\mathbf{2 0 0 8} \\
\text { Volume 3; Número } 1 \text { e } 2=9 \text { trabalhos } \\
\text { Total: } 9\end{array}$ & $\begin{array}{c}\text { 2009 } \\
\text { Volume 4; Número } 1=13 \text { trabalhos } \\
\text { Volume 4; Número } 2=11 \text { trabalhos } \\
\text { Volume 4; Número } 3=12 \text { trabalhos } \\
\text { Total: } 36\end{array}$ \\
\hline $\begin{array}{c}\text { 2010 } \\
\text { Volume 5; Número } 1=9 \text { trabalhos } \\
\text { Volume 5; Número } 2=10 \text { trabalhos } \\
\text { Volume 5; Número } 3=10 \text { trabalhos } \\
\text { Total: } \mathbf{2 9}\end{array}$ & $\begin{array}{c}\text { 2011 } \\
\text { Volume 6; Número } 1=9 \text { trabalhos } \\
\text { Volume 6; Número } 2=10 \text { trabalhos } \\
\text { Volume 6; Número } 3=13 \text { trabalhos } \\
\text { Total: } 32\end{array}$ \\
\hline $\begin{array}{c}\text { 2012 } \\
\text { Volume 7; Número } 1=14 \text { trabalhos } \\
\text { Volume 7; Número } 2=13 \text { trabalhos } \\
\text { Volume 7; Número } 3=13 \text { trabalhos } \\
\text { Volume 7; Número } 4=12 \text { trabalhos } \\
\text { Total: 52 }\end{array}$ & $\begin{array}{c}\text { 2013 } \\
\text { Volume 8; Número } 1=19 \text { trabalhos } \\
\text { Volume 8; Número } 2=17 \text { trabalhos } \\
\text { Volume 8; Número } 3=18 \text { trabalhos } \\
\text { Volume 8; Número } 4=19 \text { trabalhos } \\
\text { Total: } 73\end{array}$ \\
\hline $\begin{array}{c}\mathbf{2 0 1 4} \\
\text { Volume 9; Número } 1=18 \text { trabalhos } \\
\text { Volume 9; Número } 2=21 \text { trabalhos } \\
\text { Volume 9; Número } 3=18 \text { trabalhos } \\
\text { Volume 9; Número } 4=18 \text { trabalhos } \\
\text { Total: } \mathbf{7 5}\end{array}$ & $\begin{array}{c}\text { 2015 } \\
\text { Volume 10; Número } 1=17 \text { trabalhos } \\
\text { Volume 10; Número } 2=17 \text { trabalhos } \\
\text { Volume 10; Número Especial = } 13 \text { trabalhos } \\
\text { Total: } \mathbf{4 7}\end{array}$ \\
\hline
\end{tabular}

Fonte: Dados organizados pela autora com base nas edições da Revista Ibero-Americana.

Destes 400 trabalhos elencados na Tabela 2, apenas 76 tratavam de temáticas sobre o Ensino Médio, Educação Especial, Inclusão Escolar, Pessoa com Deficiência (os quais serviram como descritores para a seleção). Vale apontar que destes 76 artigos, 65 correspondiam a artigos nacionais e 11 eram internacionais. Dessa maneira, será apresentada, a seguir, a Tabela 3, a qual contempla a quantidade de artigos selecionados com base em cada ano, volume/número. 
Tabela 3: Total de Artigos Selecionados (2006-2015)

\begin{tabular}{|c|c|}
\hline \multicolumn{2}{|c|}{ Total de Artigos Selecionados entre os anos de 2006 a $2015=76$} \\
\hline $\begin{array}{c}\text { 2006 } \\
\text { Volume 1; Número } 1=\text { nenhum trabalho } \\
\text { Volume 1; Número } 2=1 \text { trabalho } \\
\text { Total: } \mathbf{1}\end{array}$ & $\begin{array}{c}\mathbf{2 0 0 7} \\
\text { Volume 2; Número } 1=\text { nenhum trabalho } \\
\text { Volume 2; Número } 2=3 \text { trabalhos } \\
\text { Total: } \mathbf{3}\end{array}$ \\
\hline $\begin{array}{c}\mathbf{2 0 0 8} \\
\text { Volume 3; Número } 1 \text { e } 2=1 \text { trabalho } \\
\text { Total: } \mathbf{1}\end{array}$ & $\begin{array}{c}\mathbf{2 0 0 9} \\
\text { Volume 4; Número } 1=1 \text { trabalho } \\
\text { Volume 4; Número } 2=\text { nenhum trabalho } \\
\text { Volume 4; Número } 3=3 \text { trabalhos } \\
\text { Total: } 4\end{array}$ \\
\hline $\begin{array}{c}\text { 2010 } \\
\text { Volume 5; Número } 1=5 \text { trabalhos } \\
\text { Volume 5; Número } 2=2 \text { trabalhos } \\
\text { Volume 5; Número } 3=3 \text { trabalhos } \\
\text { Total: } \mathbf{1 0}\end{array}$ & $\begin{array}{c}\text { 2011 } \\
\text { Volume 6; Número } 1=3 \text { trabalhos } \\
\text { Volume 6; Número } 2=\text { nenhum trabalho } \\
\text { Volume 6; Número } 3=2 \text { trabalhos } \\
\text { Total: } 5\end{array}$ \\
\hline $\begin{array}{c}\text { 2012 } \\
\text { Volume 7; Número } 1=3 \text { trabalhos } \\
\text { Volume 7; Número } 2=4 \text { trabalhos } \\
\text { Volume 7; Número } 3=3 \text { trabalhos } \\
\text { Volume 7; Número } 4=2 \text { trabalhos } \\
\text { Total: } 12\end{array}$ & $\begin{array}{c}\text { 2013 } \\
\text { Volume 8; Número } 1=4 \text { trabalhos } \\
\text { Volume 8; Número } 2=3 \text { trabalhos } \\
\text { Volume 8; Número } 3=5 \text { trabalhos } \\
\text { Volume 8; Número } 4=\text { nenhum trabalho } \\
\text { Total: } \mathbf{1 2}\end{array}$ \\
\hline $\begin{array}{c}\text { 2014 } \\
\text { Volume 9; Número } 1=4 \text { trabalhos } \\
\text { Volume 9; Número } 2=2 \text { trabalhos } \\
\text { Volume 9; Número } 3=1 \text { trabalho } \\
\text { Volume 9; Número } 4=2 \text { trabalhos } \\
\text { Total: } 9\end{array}$ & $\begin{array}{c}\text { 2015 } \\
\text { Volume 10; Número } 1=4 \text { trabalhos } \\
\text { Volume 10; Número } 2=2 \text { trabalhos } \\
\text { Volume 10; Número Especial = } 13 \text { trabalhos } \\
\text { Total: } \mathbf{1 9}\end{array}$ \\
\hline
\end{tabular}

Fonte: Dados organizados pela autora com base nos descritores para seleção dos trabalhos.

\section{Resultados e discussão}

Após a análise dos 76 trabalhos, constatou-se que 74 estavam dentro das temáticas de Educação Especial, Inclusão Escolar, Pessoa com Deficiência e Ensino Médio; sendo pesquisas voltadas para a educação especial (1), educação de jovens e adultos (1), estudos comparativos entre países (2), ensino fundamental (3), adequação curricular (4), sexualidade (4), prática docente (7), formação de professores (9), deficiências específicas (10), inclusão (10), ensino superior (10) e ensino médio (13).

Os 13 estudos (10 nacionais e 3 internacionais) que tratavam sobre o Ensino Médio abordavam temas variados, tais como: olhares sobre a violência do namoro; desempenho em matemática baseado nos resultados do SARESP; formação profisssional de nível médio; percepções dos professores em Portugal sobre o papel da disciplina de Biologia e do gabinete de apoio aos alunos na educação em sexualidade; diferenças de gênero e juventude; mídia-educação, uma experiência com alunos e professores; juventude, escola e mídia; indisciplina no contexto escolar; educação sexual e estudos 
de gênero no trabalho de educadores; análise de práticas educativas no ensino de Física; tutorias de alunas, uma experiência enriquecedora para melhorar os resultados e a qualidade de aprendizagem; estratégias de aprendizagem utilizadas por estudantes no âmbito científico em áreas vulneráveis do Chile; e atenção à diversidade a partir da musicoterapia.

Embora tenham sido localizadas pesquisas que traziam como cenário o Ensino Médio, pouco tem sido discutido sobre a inclusão dos alunos PAEE neste segmento educacional, uma vez que dos 76 trabalhos que foram selecionados, apenas dois estudos nacionais trataram sobre esta questão.

O primeiro estudo foi realizado pelas pesquisadoras Duarte e Manzoli (2009), publicado na edição de 2009/volume 4/número 3 da RIAEE. A temática abordada tratou da inclusão de alunos com síndrome de Down no Ensino Fundamental e Médio, o qual objetivou conhecer a situação escolar dos alunos com esta deficiência que frequentavam tais modalidades de ensino da rede pública e particular da cidade de Araraquara (SP), no que se refere aos conteúdos correspondentes às séries que estavam frequentando.

Tal pesquisa estruturou-se da seguinte forma: as autoras realizaram um levantamento desses alunos nessas redes de ensino no início de 2006, o qual mostrou que havia 7 alunos, sendo 5 da rede estadual da $2^{\mathrm{a}}, 3^{\mathrm{a}}, 4^{\mathrm{a}}, 5^{\mathrm{a}}$ e $6^{\mathrm{a}}$ séries do Ensino Fundamental, um do sexo masculino e quatro do feminino, com idades de 14 a 21 anos, e dois da rede particular: um na $5^{\mathrm{a}}$ série do Ensino Fundamental, e outro no $2^{\circ}$ ano do Ensino Médio, ambos do sexo masculino, com 17 e 18 anos, respectivamente. A técnica de pesquisa para conhecer a trajetória escolar desses alunos, bem como a situação na série que estavam frequentando, foi a entrevista com os pais e professores.

Em relação aos resultados, os dados apontaram que esses alunos frequentaram as classes especiais por um período de 3 a 15 anos, para depois serem matriculados no ensino regular, com exceção de um, que não frequentou essa classe. A pesquisa mostrou que esses alunos necessitavam de um tempo maior para a realização das tarefas, ensino individualizado, adequação curricular, bem como mudança na forma de transmitir os conteúdos e de dosar mais a quantidade das atividades para evitar o cansaço.

O segundo estudo encontrado foi desenvolvido por Cozendey; Costa e Pessanha (2013), publicado na edição de 2013/volume 8/número 2 da RIAEE. A pesquisa trouxe como tema o ensino de física para alunos surdos, cujo objetivo era discutir sobre a inclusão dos mesmos nesta disciplina, e como construir um plano de aula para o ensino da primeira lei de Newton em um ambiente inclusivo. 
Acerca do desenvolvimento da pesquisa, utilizou-se uma proposta de ensino bilíngue, na qual foi desenvolvido um plano de aula que conta com um vídeo bilíngue, situações problemas para introduzir as discussões e um questionário fechado para avaliar a aprendizagem. Participaram da pesquisa 18 alunos do $2^{\circ}$ ano do Ensino Médio de uma escola estadual do interior do estado de São Paulo (SP).

No que diz respeito aos resultados, estes mostraram que foi desenvolvida uma proposta inclusiva, uma vez que esta conseguiu assegurar a possibilidade de aprendizado a alunos com e sem deficiência auditiva, ao respeitar os ritmos e estilos de aprendizagem: foi criada uma proposta que conseguiu ensinar a todos os alunos o mesmo conceito, ao mesmo tempo.

A considerar que alunos com síndrome de Down e surdos fazem parte dos sujeitos público-alvo da Educação Especial, estes foram os dois estudos encontrados que se enquadravam nos critérios que o presente trabalho buscou investigar. Dessa forma, pode-se afirmar que é necessário expandir os estudos sobre esta temática, visto que estes alunos estão conseguindo alcançar este segmento educacional, conforme demonstrado com os dados do Censo Escolar.

\section{Considerações finais}

Conforme o que foi apresentado, verificou-se que existe uma variedade muito grande de temáticas entre as produções científicas. No entanto, os dados revelaram um número reduzido de trabalhos referentes à inclusão escolar no contexto do Ensino Médio.

Dentre os estudos analisados, verificou-se que os professores estão tentando tornar o ambiente escolar mais inclusivo para receber os alunos PAEE, e mais do que isso, estão buscando formas para ensiná-los e lhes propiciar uma educação de qualidade. Entretanto, a instituição escolar ainda precisa sofrer reestruturações, os professores necessitam conhecer mais sobre as características e especificidades das deficiências, para que assim possam estabelecer os melhores caminhos e práticas para ensinar estes alunos, principalmente no contexto do Ensino Médio.

Para tanto, conclui-se que os estudos acerca da inclusão dos alunos PAEE no Ensino Médio precisam ser expandidos, uma vez que há campo para ser explorado e pesquisado, o que ocasionará uma grande contribuição para a área educacional, e principalmente para a Educação Especial. 


\section{REFERÊNCIAS}

BRASIL. INEP. Censo escolar da educação básica 2013: resumo técnico. Brasília, 2014a.

BRASIL. Plano Nacional de Educação. Ministério da Educação / Secretaria de Articulação com os Sistemas de Ensino (MEC/SASE), 2014b.

BRASIL. Diretrizes Curriculares Nacionais Gerais da Educação Básica/ Ministério da Educação. Secretaria de Educação Básica. Diretoria de Currículos e Educação Integral. - Brasília: MEC, SEB, DICEI, 2013.

BRASIL _. Conselho Nacional de Educação. Resolução CNE/CEB n.2/2012, de 30 de janeiro de 2012. Institui diretrizes curriculares nacionais para o Ensino Médio. Diário Oficial da União, Brasília, 2012.

BRASIL. Congresso Nacional. Decreto $\mathbf{n}^{\circ} \mathbf{7 6 1 1}$, de 17 de novembro de 2011. Dispõe sobre a educação especial, o atendimento educacional especializado e dá outras providências. Brasília, 2011.

BRASIL. Congresso Nacional. Decreto $\mathbf{n}^{\circ}$ 6949, de 25 de agosto de 2009. Promulga a Convenção Internacional sobre os Direitos das Pessoas com Deficiência e seu Protocolo Facultativo, assinados em Nova York, em 30 de março de 2007. Brasília, 2009.

BRASIL. Congresso Nacional. Lei de Diretrizes e Bases da Educação (Lei 9.394/96). Brasília: Centro Gráfico, 1996.

BRASIL. Constituição (1988). Constituição da República do Brasil. Brasília, DF: Senado, 1988.

COZENDEY, S. G.; COSTA, M. P. R.; PESSANHA, M. C. R. Ensino de Física e Educação Inclusiva: o Ensino da primeira Lei de Newton. Revista Ibero-Americana de Estudos em Educação, v. 8, n. 2, 2013.

DUARTE, M.; MANZOLI, L. P. A inclusão do aluno com síndrome de Down: um estudo sobre a situação escolar no ensino fundamental e médio da cidade de Araraquara - SP. Revista Ibero-Americana de Estudos em Educação, v. 4, n. 3, 2009.

KOLLER, S. H.; COUTO, M. C. P. P.; HOHENDORFF, J. V. Manual de produção científica/ Organizadores, Sílvia H. Koller, Maria Clara P. de Paula Couto, Jean Von Hohendorff. - Porto Alegre: Penso, 2014.

MENDES, E. G. A radicalização do debate sobre inclusão escolar no Brasil. Revista Brasileira de Educação, v. 11, n. 33, set./dez., 2006. 


\section{Como referenciar este artigo}

FELICIO, Natália Costa de.; CAMPOS, Juliane Aparecida de Paula Perez. A inclusão escolar no contexto do Ensino Médio: análise das produções em periódico científico. Revista Ibero-Americana de Estudos em Educação, Araraquara, v. 12, n.3, p. 17101720, jul-set/2017. Disponível em: <http://dx.doi.org/10.21723/riaee.v12.n.3.2017.8516>. E-ISSN: 1982-5587.

Submetido em: 12/04/2016

Aprovação final em: 09/06/2017 